\title{
Diversidade cultural e a preservação de acervos audiovisuais do eixo sul ${ }^{1}$
}

\author{
Diversidad cultural y la preservación de acervos audiovisuales $\quad$ del \\ eje sur
}

Cultural diversity and the preservation of audiovisual collections of the southern axis

\author{
Laura Bezerra ${ }^{2}$ \\ Joanderson da Silva Santos ${ }^{3}$
}

\begin{abstract}
Resumo
O artigo proposto desenvolve algumas reflexões a partir dos resultados de três etapas da pesquisa "Preservação Audiovisual entre o Global e o Local": a) análise do Programa Mercosul Audiovisual, que inseriu a "conservação do patrimônio regional" entre seus objetivos centrais; b) as políticas brasileiras para a preservação audiovisual, chegando até c) suas reverberações na esfera local, na produção audiovisual do Estado da Bahia. Através de revisão de literatura, análise documental e entrevistas com pessoas-chave buscamos entender qual o lugar da preservação audiovisual nessas três esferas, com ênfase nas propostas concretas de atuação setorial e seus resultados. A indagação que nos guia é qual a consequência das políticas de preservação audiovisual (ou sua ausência) para a diversidade cultural dos países do Mercosul, em especial o Brasil?
\end{abstract}

Palavras-Chave: Cinema; Diversidade; Mercosul; Política cultural; Preservação audiovisual.

\section{Resumen}

El artículo propuesto desarrolla algunas reflexiones a partir de los resultados de tres etapas de la investigación "Preservación Audiovisual entre el Global y el Local": a) análisis del Programa Mercosur Audiovisual, que insertó la "conservación del patrimonio regional" entre sus objetivos centrales; b) las políticas brasileñas para la preservación audiovisual, llegando hasta c) las reverberaciones en la esfera local, en la producción audiovisual de la Provincia de Bahía. Basado en la revisión de literatura, análisis documental y entrevistas con personas clave buscamos entender cuál es el lugar de la preservación audiovisual en esas tres esferas, con énfasis en las propuestas concretas de acción sectorial y sus resultados. La indagación que nos guía es cuál es la consecuencia de las políticas de preservación audiovisual (o su ausencia) para la diversidad cultural de los países del Mercosur, en especial para Brasil?

Palabras clave: Cine; Diversidad; Mercosur; Política cultural; Preservación audiovisual.

\begin{abstract}
The article develops some reflections arising from the results of three phases of the research "Audiovisual Preservation between the Global and the Local": a) analysis of the Mercosur Audiovisual Program, which inserted the "conservation of regional audiovisual heritage" among its central objectives; b) Brazilian policies for

\footnotetext{
${ }^{1}$ Artigo apresentado no II Seminário Latino-Americano de Estudos em Cultura - SEMLACult em Foz do Iguaçu/PR, Brasil, 2018.

${ }^{2}$ Doutora em Cultura e Sociedade pela Universidade Federal da Bahia; professora adjunta do Centro de Cultura, Linguagens e Tecnologias Aplicadas da Universidade Federal do Recôncavo da Bahia (UFRB); coordenadora dos projetos "Preservação Audiovisual entre o Global e o Local" e "Filmografia Baiana"; Salvador/Santo Amaro, Bahia, Brasil; laura.bezerra@ufrb.edu.br.

${ }^{3}$ Egresso do Bacharelado Interdisciplinar em Cultura, Linguagens e Tecnologias Aplicadas da UFRB; participou como voluntário de Iniciação Científica dos projetos de pesquisa "Preservação Audiovisual entre o Global e o Local” e "Filmografia Baiana"; Bertioga, São Paulo, Brasil; piropo_joanderson@ hotmail.com.
} 
audiovisual preservation, reaching up to c) their reverberations in the local sphere, in the audiovisual production of the State of Bahia. Through literature review, documentary analysis and interviews with key people, we sought to understand the place of audiovisual preservation in these three spheres, with emphasis on concrete proposals for sectoral action and its results. The question that guides us is what is the consequence of the policies of audiovisual preservation (or its absence) for the cultural diversity of the Mercosur countries?

Keywords: Cinema; Audiovisual Preservation; Cultural Diversity; Cultural Policy; Mercosur (Southern Common Market).

\title{
1. Introdução: A diversidade cultural como desafio
}

\begin{abstract}
A diversidade cultural constitui grande riqueza para os indivíduos e as sociedades. A proteção, promoção e manutenção da diversidade cultural é condição essencial para o desenvolvimento sustentável em benefício das gerações atuais e futuras. (UNESCO, 2005, p. 4).
\end{abstract}

Os intensos debates em torno da Declaração Universal sobre a Diversidade Cultural (2002) e da Convenção para a Proteção e a Promoção da Diversidade das Expressões Culturais (2005) deixaram marcas palpáveis nas políticas culturais. A ideia da diversidade cultural como "patrimônio comum da humanidade, a ser valorizado e cultivado em benefício de todos" (UNESCO, 2005, p. 2), vem sendo utilizada por diversos grupos em busca do reconhecimento de diferenças e da efetivação de direitos, especialmente por aqueles com bens e manifestações sob ameaça.

Entretanto, com uma visão amável e "ecumênica" de diversidade entendida como variedade - expressa, por exemplo, no multiculturalismo das propagandas da Benetton -, a "diversidade cultural" transformou-se em uma espécie de slogan. Alguns autores insistem na necessidade de se refletir sobre o "entusiasmo conceitual" que ela sucitou e rever criticamente o conceito, devolvendo a ele sua "conflitualidade" (BERNARD, 2005, p. 74; BARROS; ZIVIANI, in: CALABRE, 2009, p. 112). Nossa pesquisa de doutorado sobre as políticas de presevação audiovisual no Brasil, que tentou localizar o lugar do patrimônio audiovisual nas políticas de salvaguarda do patrimônio cultural do país, caminhou nesse mesmo sentido e evidenciou um processo marcado por conflitos e disputas (BEZERRA, 2013).

Em uma ordem mundial marcada por fortes desigualdades, deve-se sublinhar que a “diversidade cultural é, do ponto de vista antropológico, o mais rico patrimônio da humanidade, mas do ponto de vista politico e econômico, constitui-se também como um de seus maiores desafios” (BARROS; DUPIN; KAUARK, 2017, p. 14). Se, por um lado a Convenção defende que a "diversidade cultural cria um mundo rico e variado que aumenta a 
gama de possibilidades e nutre as capacidades e valores humanos, constituindo, assim, um dos principais motores do desenvolvimento sustentável das comunidades, povos e nações" (UNESCO, 2005, p. 1), por outro lado, é inegável o "desequilíbrio existente entre uma abordagem dominante centrada no mercado capitalista e outra baseada na promoção de bens comuns compartilhados" (ALBORNOZ, in: KAUARK; BARROS; MIGUEZ, 2015, p. 160). Não por acaso, o audiovisual esteve no centro dos debates sobre a "exceção cultural"; ele é parte de "um gigantesco mercado que, dominado por grandes conglomerados de produção e distribuição de conteúdos culturais, funciona em escala global e movimenta cifras astronômicas" (MIGUEZ, 2011, p. 61).

O artigo proposto desenvolve algumas reflexões a partir dos resultados de três etapas da pesquisa "Preservação Audiovisual entre o Global e o Local": a) análise do Programa Mercosul Audiovisual, que inseriu a "conservação do patrimônio regional" entre seus objetivos centrais; b) as políticas brasileiras para a preservação audiovisual, chegando até c) suas reverberações na esfera local, na produção audiovisual do Estado da Bahia. Através de revisão de literatura, análise documental e entrevistas com pessoas-chave buscamos entender qual o lugar da preservação audiovisual nessas três esferas, com ênfase nas propostas de atuação setorial e seus resultados. A indagação que nos guia é qual a consequência das políticas de preservação audiovisual (ou sua ausência) para a diversidade cultural dos países do Mercosul

\section{Preservação audiovisual no eixo sul}

A cooperação e a solidariedade internacionais devem permitir a todos os países, em particular os países em desenvolvimento, criarem e fortalecerem os meios necessários a sua expressão cultural - incluindo as indústrias culturais, sejam elas nascentes ou estabelecidas - nos planos local, nacional e internacional. (UNESCO, 2005, p. 4).

Nossas reflexões se desenvolveram em torno do Plano Estratégico Patrimonial (PEP) elaborado como parte do Programa Mercosul Audiovsiual (PMA). Adotamos, neste artigo, a definição de preservação audiovisual proposta por Carlos Roberto de Souza, pesquisador e preservador da Cinemateca Brasileira, em sua tese de doutorado:

o conjunto dos procedimentos, princípios, técnicas e práticas necessários para a manutenção da integridade do documento audiovisual e garantia permanente da possibilidade de sua experiência intelectual. [...] A preservação engloba a prospecção e a coleta, a conservação, a duplicação, a restauração, a reconstrução (quando necessária), a recriação de condições de 
apresentação, e a pesquisa e a reunião de informações para realizar bem todas essas atividades. (SOUZA, 2009, p. 6).

Este trabalho é realizado por arquivos audiovisuais, definidos por Ray Edmondson, ex-diretor-adjunto da National Film and Sound Archive da Austrália, como:

\begin{abstract}
organização ou um departamento de uma organização cuja missão, eventualmente estabelecida por lei, consiste em facilitar o acesso a uma coleção de documentos audiovisuais e ao patrimônio audiovisual, mediante atividades de reunião, gestão, conservação e promoção. (Edmondson, 2013, p. 86).
\end{abstract}

Numa versão anterior da publicação, ${ }^{4}$ Edmondson $(1998$, p. 8) fez questão de ressaltar um aspecto central: “[...]colecionar / administrar / preservar / fornecer acesso a documentos audiovisuais é seu objetivo principal e não uma atividade suplementar no meio de outras. A palavra de ligação é e, não ou: o arquivo faz tudo, não algumas destas coisas. (grifos do autor)." Diferente da ideia, bastante difundida, de cinematecas como guardiãs de "latas velhas", na percepção dos profissionais da preservação, as ações em prol da salvaguarda de acervos audiovisuais têm como objetivo maior a "garantia permanente da possibilidade de sua experiência intelectual", ou seja, o acesso aos filmes.

Antes de falarmos sobre o Plano, três breves notas sobre a preservação audiovisual. Em primeiro lugar, entendemos que arquivos audiovisuais e cinematecas realizam uma operação historiográfica, uma seleção do que estará ou não disponível para as gerações futuras (LEGOFF, 1996), com consequências diretas para a diversidade cultural no geral e, mais especificamente, para a produção audiovisual de cada país.

Em segundo lugar, é importante destacar que arquivos audiovisuais e cinematecas estão organizados internacionalmente desde 1938, quando da criação da Federação Internacional dos Arquivos Fílmicos (FIAF), que congrega, atualmente mais de 150 arquivos de todas as regiões do mundo e tem um papel importante para a sistematização e difusão dos conhecimentos do/para o setor. ${ }^{5}$ Um estudo de 2006 aponta para a existência pelo menos 32 cinematecas iberoamericanas, "además de decenas, tal vez cientos, de otros archivos fílmicos com preocupaciones de orden técnico em la preservación de sus acervos.” (GALVÃO, 2006).

\footnotetext{
${ }^{4}$ Produzido sob auspícios da UNESCO e em consulta com um grupo de preservadores audiovisuais de diversos países, vinculados ao Co-ordinating Council of Audiovisual Archives Associations (CCAAA). Uma versão atualizada foi publicada no Brasil, em 2013, pela Associação Brasileira de Preservação Audiovisual (ABPA)/Cinemateca do MAM-RJ.

${ }^{5}$ Por exemplo, com publicações como o Glossário de Termos Fílmicos (com verbetes em doze línguas), Regras de Catalogação para Arquivos de Filmes (com versões em inglês, francês e espanhol), ou Technical Manual of the Fiaf Preservation Commission (um manual de preservação de cinema e vídeo com versões em inglês e francês).
} 
Uma associação regional, a Coordinadora Latinoamericana de Archivos de Imágen en Movimiento (Claim) existe desde 1985. Assim, a preservação audiovisual, desde seus inícios, articulou internacionalmente ações realizadas por instituições públicas e privadas.

Por outro lado - e finalmente - , observamos que as instituições detentoras de acervos audiovisuais "têm histórias marcadas por crises sucessivas, falta crônica de recursos e fragilidade institucional” (BEZERRA, 2013, p. 17). Cabe, ainda, salientar que os países do Mercosul estão em estágios muito diferentes de organização setorial. ${ }^{6}$

O Programa Mercosul Audiovisual (PMA), instituído pela Reunião Especializada de Autoridades Cinematográficas e Audiovisuais do Mercosul (Recam), em 2009, inseriu a “conservação do patrimônio audiovisual da região" entre seus quatro objetivos centrais. Como consequência, foi elaborado o Plano Estratégico Patrimonial (PEP), finalizado no final de 2013, que afirma a preservação audiovisual como quarta coluna na construção de uma "política audiovisual progressista" e defende a valorização a memória e das imagens próprias dos países do Mercosul, bem como o fomento à diversidade na produção e consumo, (RECAM, 2013, p. 4 e 10, tradução nossa).

Em que medida, nos perguntamos, o PEP se articula na esfera das instituições detentoras de acervos audiovisuais do Mercosul (visto que é aqui que se realizam ações de preservação) e qual sua contribuição para "a manutenção da integridade do documento audiovisual e garantia permanente da possibilidade de sua experiência intelectual"? (SOUZA, 2009, p. 6). Antes de tecermos algumas reflexões sobre o Plano, cabe ressaltar que os processos políticos, assim como estruturas e interesses institucionais influenciaram as estratégias escolhidas pela coordenação do programa, sendo, portanto, determinantes para as ações e medidas efetivamente implementadas. ${ }^{7}$ Somente a inter-relação entre esses três

\footnotetext{
${ }^{6}$ À época de elaboração do Plano Estratégico Patrimonial, o Brasil vivia um momento de valorização da Cinemateca Brasileira, organização federal, vinculada ao Ministério da Cultura, responsável pela salvaguarda do patrimônio audiovisual brasileiro, além de estar um momento muito vívido de organizaçao setorial que culminou na criação da Associação Brasielira de Preservação Audiovisual (ABPA), em 2008, e elaboração de um Plano Nacional de Preservaçao Audiovisual em 2016. No Uruguai, as instituições detentoras de acervos audiovisuais, públicas e privadas, capitanaeadas pelo órgão nacional, o Archivo Nacional de la Imagen y la Palabra (dependência do SODRE, unidade executora do Ministério de Educação e Cultura), haviam elaborado um diagnóstico da situação no país e apresentado propostas para uma política de preservação. Na Argentina, contudo, ainda se tentava criar uma instituição nacional de preservação. Nas palavras de uma gestora deste país, “...me hace gracía el hecho de que que fue un equipo argentino [a coordenar as ações...] Nosotros no tenemos políticas instaladas, no hemos sido capaces de tener una política de Estado. Somos muy pocos los que sabemos algo de esto y no estamos capacitados formalmente [...] Nosotros ni sabemos quiénes somos [as instituições detentoras de acervos audiovisuais]." (Arg-Gestor/a 1)

${ }^{7}$ Extrapolaria os limites deste artigo, aprofundar este tema, por isso apenas apontamos que nos parece produtivo, nas análise de políticas públicas, buscar compreender o "grau de influência das estruturas políticas ('polity') e dos processos de negociação política ('politics') sobre as políticas efetivamente implementadas,
} 
aspectos, nos permite entender algumas formulações e aspectos do Plano Estratégico Patrimonial, que parecem incongruentes para profissionais atuantes na preservação audiovisual.

O objetivo geral do Plano foi "definir as linhas estratégicas referentes à conservação, restauração e digitalização do seu patrimônio audiovisual, por meio de recomendações aos Estados-Membros do Mercosul” (RECAM, 2013, p. 9), contudo ele apresenta incongruências significativas e seu potencial como política cultural foi limitado por três aspectos, que apresentamos aqui sucintamente: ${ }^{8}$ em primeiro lugar, "indefinições conceituais [que] impedem que o PEP tenha um foco preciso e que levaram a uma estruturação problemática do documento, ${ }^{9}$ [em segundo,] discrepâncias entre seu objetivo geral e específicos" (BEZERRA, 2016, p. 161). Finalmente, enquanto documento de planejamento e gestão há duas lacunas significativas, a ausência de metas e de fontes de recursos, o que restringe sobremodo a realização de ações concretas e impede seu monitoramento e avaliação.

Se entendemos uma política cultural como articulação entre formulações e práticas, nossa pesquisa sobre o PEP aponta para resultados concretos bastante reduzidos. Um plano não é uma carta de intenções; “os planos, programas e projetos na administração pública são formas de organizar toda estratégia governamental para dar cumprimento às políticas públicas que precisam ser implementadas." (AGUILAR, 2012, p. 382, grifos nossos). Cabe salientar que as entrevistas realizadas com preservadores audiovisuais da Argentina e

dimensão conhecida como 'policy' (Cf. FREY, 2000). Problemático nos parece no caso específico, em primeiro lugar, que o Plano Estratégico Patrimonial tenha sido elaborado por uma equipe puramente argentina, o país, dos quatro envolvidos, menos desenvolvido nesse setor - o único que não possuía uma instituição pública nacional de preservação audiovisual. Em segundo, e isso é consequência direta do ponto anterior, por pessoas desvinculadas do mundo dos arquivos audiovisuais e sem formação específica. Cf. o depoimento de uma preservadora argentina na nota de rodapé anterior. Caberia olhar com mais vagar o processo licitatório que definiu a coordenação do Plano. Em entrevista, o gestor do PMA, conta que "las licitaciones se llevaron con posibilidad de participación de los países, de integrantes de los países. Se les pidió a los países que designaran quienes querían participar en esa licitación." Contudo, como mostrou nossa investigação, os profissionais de preservação brasileiros sequer tinham conhecimento do processo. No contexto da policy analisis, alguns aspectos precisariam ser considerados: por exemplo, que o Instituto Nacional de Cine y Artes Audiovisuales (INCAA), que coordenou o Programa Mercosul Audiovisual, teve que criar estruturas novas para possibilitar a articulação entre os países; que as recorrentes trocas de interlocutores nos países, motivados por câmbios politicos internos, dificultou os fluxos; que as legislações nacionais representam uma dificuldade extra para as articulações desejadas. Além dos interesses específicos das autoridades audiovisuais de cada país, representados na RECAM, pois "los organismos que, de alguna manera, podrían estar siendo demandados, cobrados, como decís vos, son los mismos que tendrían que aprobarlo, quienes participan en la RECAM”. (Entrevista com Nancy Caggiano e Guillermo Saura, em 11 de dezembro de 2015, na sede o INCAA).

\footnotetext{
${ }^{8}$ Informações mais detalhadas em BEZERRA, 2015. No artigo, analiso o PEP a partir de dois pontos de vista: sua viabilidade enquanto documento de política pública e na perspectiva da preservação audiovisual.

${ }^{9}$ O Plano não define preservação e o entendimento implícito no documento é bem distante do dos profissionais do setor, que como vimos, há muitos anos está empenhado em sistematizar e difundir suas bases de atuação.
} 
Uruguai ${ }^{10}$ expuseram descrédito com o processo e com as possíveis reverberações práticas do Plano. Nas palavras de uma gestora argentina:

Entonces, si bien me parece que es una gran idea la de tener un Plan Estratégico del Mercosur, que también estamos empezando como poniendo la carreta delante del caballo, porque el primer trabajo era hacer lo que ya había hecho Uruguay, un revelamiento: en qué estado estamos, dónde hay patrimonio, cuánto hay, qué instituciones se ocupan de eso. En Argentina no lo tenemos. (Arg-Gestor/a 1)

Preservadores uruguaios foram mais longe: "não creio que terá nenhum resultado concreto" (Uru-Gestor/a 2) e "tenho a impressão que foi feito apenas para constar em algum relatório"(Uru-Gestor/a 5).

Por outro lado, entendemos que a mera abordagem da preservação como parte das políticas de audiovisual do Mercosul poderia contribuir para a construção de modelos contrahegemônicos, tendo em vista que, como afirma Mariella Pitombo Vieira (2009, p. 224), tratados internacionais podem potencialmente "produzir e estruturar habitus específicos e, por consequência, redefinir práticas sociais e produzir subjetividades”. O Plano poderia, por exemplo, levar ao agendamento do tema nas diversas instâncias de atuação do mercado ou da política audiovisual, seja na esfera regional, nacional ou local, ou ainda mobilizar os atores envolvidos em torno de ações concretas.

Por isso, em um segundo momento da nossa investigação, buscando entender esses possíveis efeitos difusos do Plano Estratégico Patrimonial em um dos países, em 2016, contactamos os membros da Associação Brasileira de Preservação Audiovisual (ABPA), ${ }^{11}$ que congrega profissionais de todo o país, perguntando como avaliavam seu potencial enquanto instrumento de planejamento e gestão. ${ }^{12}$ Com exceção de membros de duas

\footnotetext{
${ }^{10}$ Foram realizadas entrevistas com preservadores audiovisuais brasileiros, em 2013, no contexto da minha pesquisa de doutoramento. Os depoimentos de pessoas-chave da preservação audiovisual da Argentina e Uruguai, foram colhidos entre 2015-2016, como parte do projeto "Preservação audiovisual entre o global e o local (I): Políticas de preservação audiovisual em países latino-americanos (Argentina, Brasil, Paraguai e Uruguai) e a influência de instâncias transnacionais". Entre 2016-2017, entrevistamos seis realizadores baianos, com idades e perfis diversos (homens e mulheres, entre 22 e 67 anos, da capital e interior) para a Filmografia Baiana.
}

${ }^{11}$ A ABPA foi criada em 2008 e, desde então, reúne anualmente preservadores audiovisuais de todo o Brasil, que, em 2016, elaboraram um Plano Nacional de Preservação Audiovisual. Cf. <http://www.abpreservacaoaudiovisual.org/site/>. Acesso em: jul. 2018.

${ }^{12}$ Em e-mail postado na lista da ABPA em setembro de 2015, fizemos as seguintes perguntas: 1. Você conhece o Plano Estratégico Patrimonial do Programa Mercosul Audiovisual? Caso a resposta seja positiva: 2. Como esta iniciativa pode contribuir para uma melhoria da preservação audiovisual no Mercosul? 3. Que impacto ele teve para sua instituição? Para além desta consulta geral, enviamos um e-mail separado para membros da ABPA vinculados às seguintes instituições: Arquivo Nacional (instituição federal/Rio de Janeiro); CTAv (instituição federal/Rio de Janeiro); Cinemateca do MAM-RJ (instituição privada/Rio de Janeiro); Núcleo de Memória da FUNCEB (instituição estadual/Bahia); Centro de Referência Audiovisual , 
instituições, a Cinemateca Brasileira, órgão federal diretamente envolvido no processo, e a Cinemateca do MAM-RJ, os preservadores, mesmo aqueles vinculados a instituições públicas federais, desconheciam não somente seu processo de construção, mas também a própria existência do Plano. Para Hernani Heffner, apesar da Cinemateca do MAM não estar habilitada a participar por ser uma instituição privada, o Plano seria "meritório", se conseguisse estimular articulações institucionais. Ele poderia contribuir

\begin{abstract}
...se for melhor organizado e [se] a restauração foto-química for a premissa e não uma simples telecinagem... Bem entendido, claro, que isto [a telecinagem] é melhor do que nada, mas se for a sério, será muito mais do que isso e a custos muito baixos, pois os equipamentos estão aí desde o México - UNAM - até o Brasil - Cinemateca Brasileira.
\end{abstract}

Esta resposta aponta para questões muito básicas da preservação, deixando evidente o quanto as ações concretas propostas, ${ }^{13}$ no centro das quais estava a feitura de um DVD com filmes de vários países do Mercosul, estavam desvinculadas das necessidades e das demandas setoriais. Na verdade, sequer partiam do conhecimento estabelecido sobre o que seria preservação audiovisual. O comentário argentino foi no mesmo sentido do citado acima:

\begin{abstract}
Y me parecía muy exiguo, o sea, mucho dinero en el Programa para terminar solo digitalizando 110 minutos [...], y que no implicaba en hacer internegativo, ni hacer todo el trabajo de preservación, sino sólo digitalizar, [materiales que] tenían que estar medianamente en buenas condiciones.[...] Entonces la verdad esto me parecía como superficial y que realmente no terminaba de ayudar a la causa (Arg-Gestor/a 1, grifos nossos).
\end{abstract}

Em um terceiro momento da nossa investigação, entramos em contato com os realizadores, visto que, os últimos anos vem se fortalecendo a ideia da preservação como elo constituinte da cadeia produtiva do audiovisual. ${ }^{14}$ Nesse sentido, considerando a preservação audiovisual não como um ato, mas como um processo que começa na produção, buscamos, no

vinculado à Fundação Municipal de Cultura da Prefeitura de Belo Horizonte (instituição municipal/Minas Gerais); Cinemateca do Instituto Cultural Lula Cardoso Ayres (instituição privada/Pernambuco).

${ }^{13}$ Além da elaboração do Plano (com as limitações apontadas); a recomendação do dia 27 de outubro como Dia do Patrimônio Audiovisual do Mercosul (sendo que, desde 2005, se comemora, nesta data, o Dia Mundial do Patrimônio Audiovisual); e da criação de uma base de dados comum (que não está sendo usada), o que ocupou uma posição central deste eixo do PMA foi a digitalização de materiais para feitura de um DVD com filmes dos quatro países. Algumas decisões (a criação do banco de dados e do DVD) mostram que, dentro do Programa Mercosul Audiovisual, a preservação ocupava um lugar subalterno: a digitalização de materiais analógicos não configura uma ação de preservação, mas, sim, de difusão. A serventia do banco de dados está também conectada com a difusão e com a proposta de criação de uma rede de salas de exibição digital.

${ }^{14}$ Entre as resoluções do VII Congresso Brasileiro de Cinema (São Roque, 2007), há a recomendação expressa "que a comunidade audiovisual utilize nos seus pronunciamentos e publicações a expressão: "produção, distribuição, exibição e preservação' quando se referir ao ciclo cinematográfico.” 
âmbito do projeto Filmografia Baiana, ${ }^{15}$ entrevistar diretores e produtores atuantes no Estado da Bahia, a fim de levantar informações sobre como preservam seus filmes e como avaliam as políticas para salvaguarda do acervo fílmico do Mercosul, do Brasil e da Bahia.

Não apenas o Plano Estratégico Patrimonial era desconhecido, como também encontramos pouco conhecimento das políticas e a organização setoriais, mas havia um interesse difuso na preservação: "Ficar produzindo, produzindo, produzindo sem cuidar do que já foi feito é uma burrice, porque a gente não pode desconhecer o nosso passado, a gente não pode pensar, fazer, criar (...) sem tá tendo contato com tudo que já foi feito antes" (BahiaDiretor/a 6). Esta fala já reflete mudanças na percepção do lugar da preservação. Um realizador de outra geração conta que, nos anos 1970-1980 havia uma "filosofia parecida com a [da geração] mimeógrafo na poesia [...] só existia aquela coisa de circular [com os filmes]. (Bahia-Diretor/a 2).

Independente da postura individual, todos os diretores e diretoras entrevistados lamentaram a falta de uma política e de estruturas adequadas para a preservação do acervo estadual. Esta é uma lacuna, que leva a perdas graves, por exemplo o filme Fibra, ${ }^{16}$ curtametragem documental, de 1986, realizado em 16mm, sobre operários mutilados pelas máquinas de processamento do sisal. $\mathrm{O}$ filme, esteticamente muito interessante e premiado em festivais, teve um impacto social inusitado para um filme: "a partir [...] de toda essa mobilização que o filme fez, se conseguiu colocar um equipamento na máquina, que diminuiu em $90 \%$ os processos de mutilação, então a gente tem muito orgulho disso."17

Este filme, de relevância estética e social, teve seu negativo de som destruído e está praticamente perdido. Quem não viu, não o verá mais. Se lamentamos as perdas dos filmes feitos em película, é preciso sublinhar com toda ênfase, que as ameaças se agravam quando se fala do mundo digital:

nessa época digital eu acho muito difícil [preservar], é sempre uma "bateção" de cabeça, uma "loucurada" com HD, isso gera muito material também. Acho que o digital ele trouxe essa questão de ter a facilidade da produção. No, entanto acho que isso traz uma quantidade de material que acaba ficando impossível armazenar (...) [Bahia-Diretor/a 1]

\footnotetext{
${ }^{15}$ A Filmografia Baiana tem como objetivo principal coletar, sistematizar e divulgar informações sobre a produção audiovisual da Bahia desde seus primórdios. Cf. <http://filmografiabaiana.com.br〉. Acesso em: jul. 2018.

${ }^{16} \mathrm{Cf}$. a página do filme na FB: http://filmografiabaiana.com.br/DetalheFilme.aspx?id=56

${ }^{17}$ Entrevista com o diretor Fernando Belens, realizada por Joanderson Santos, em maio de 2016, em Salvador.
} 
A dificuldade, entretanto, não é somente a capacidade de armazenamento, mesmo que essa seja uma questão importante, e que implica na disponibilidade de recursos financeiros para investir no armazenamento. Além disso, há o problema da rápida obsolescência dos formatos digitais com a necessidade constante de migração de formatos, algo também atrelado a custos. Pouco se sabe, com segurança, sobre a vida útil dos produtos digitais, mas, diferente dos analógicos, que se decompõem lenta e visivelmente, eles deterioram de uma vez, sem emitir sinais de alerta. Hernani Heffner, Conservador da Cinemateca do MAM, chama a atenção para o fato que começa a se repetir com as chamadas novas mídias os velhos problemas de preservação do cinema feito em película. Segundo ele, "os primeiros games nacionais estão desaparecidos [... e] as fitas HD do primeiro longa metragem eletrônico feito entre nós foram apagadas" (HEFFNER, 2007, p. 3). Aos já conhecidos desafios da preservação analógica, juntam-se as inseguranças na conservação de longo prazo do material digital e à complexificação da formação do preservador audiovisual.

A salvaguarda dos acervos audiovisuais é fundamental para a constituição das cinematografias nacionais diversas, seja porque é "através da preservação e a consequente possibilidade de acesso aos filmes produzidos no país, que se constrói uma história comum; [... ou porque] o contato com diferentes épocas e vertentes do cinema, do país ou de fora dele, influencia a própria produção local.” (BEZERRA, 2013, p. 18). Nas palavras de uma jovem diretora:

\footnotetext{
acho importante conhecer isso tudo [...], a gente referenciar mesmo o que foi feito por esforço desses desbravadores mesmo do nosso cinema, [...], conhecer um pouco como a linguagem foi mudando a depender dos contextos políticos, históricos da época, da tecnologia, a gente acompanhar e entender esse movimento, até pra entender o momento que a gente tá, o que já se fez, o que se esgotou, o que já não é novo (...) e por isso que eu sinto falta desses espaços como a cinemateca (...) que faz a memória estar viva, circulando (...) (Bahia-Diretor/a 6)
}

Já se escreveu sobre a importância da Cinematheque Française para a produção da Nouvelle Vague (DE BAEQUE) ou das exibições da Cinemateca do MAM-RJ para o Cinema Novo (ROCHA) e a diretora acima citada aponta a necessidade de descentralização das instituições de salvaguarda: seria "interessante a existência de uma cinemateca na Bahia, ou no Nordeste pra gente descentralizar esse conhecimento, esse saber e essa produção, fica tudo lá [em São Paulo], a gente não tem acesso" (Bahia-Diretor/a 6). Além do acesso, surgiu, nas entrevisats, outro aspecto relevante: “... se a gente tem uma única grande cinemateca [a Cinemateca Brasileira, de São Paulo], é obvio que poucas coisas vão pra lá (Bahia-Diretor/a $5)$. 
Se "poucas coisas" são preservadas, seria importante refletir sobre quais são elas e quais os critérios de seleção do que é digno ou não de permanecer, especialmente se considerarmos que o mercado audiovisual é dominado por seis empresas estadunidenses e que $80 \%$ dos filmes exibidos em todo o mundo vem de Hollywood, impondo não somente conteúdos, narrativas e valores, mas também formatos e padrões estéticos. Aspecto importante, trazido por um jovem diretor independente

\begin{abstract}
eu acho que o grupo ao qual eu estou incluído [“do independente do independente"] é um grupo de menos interesse da história, da memória do audiovisual, por relações de poder mesmo [...] Se existe um grande gargalo de circulação? Se as distribuidoras de cinema só falam em longa-metragem, já que curta não vai pra cinema? Se as distribuidoras de cinema são praticamente todas majors norte-americanas? Como é que o filme vai chegar na exibição para que as pessoas tenham conhecimento dos filmes e possam iniciar um processo de salvaguarda do filme? (Bahia-Diretor/a 5).
\end{abstract}

Também nessa perspectiva, a descentralização surge como via possível:

\begin{abstract}
se a gente tem várias instituições distribuídas pelo país [...a gente teria tanto] as múltiplas produções do cinema paulista (que são muitas) armazenadas, arquivadas com os seus devidos cuidados, quanto as produções que são feitas pelos índios Kuikuru [...] uma articulação em rede, é um trabalho de investimento em polos. Eu acho que seria uma boa alternativa porque você tem mobilizadores locais [...], se você descentraliza o poder aí tem uma oportunidade maior de anônimos como eu permanecer na história. (BahiaDiretor/a 5).
\end{abstract}

Essa fala está alinhada com as propostas do Plano Nacional de Preservação Audiovisual, que recomendam o investimento em "um processo descentralizado de preservação audiovisual no país, fomentando e apoiando as cinematecas e arquivos audiovisuais regionais ${ }^{18 ", ~ q u e ~ c o n e c t a d a s ~ p o r ~ " p r i n c i ́ p i o s ~ d e ~ g o v e r n a n c ̧ a ~ c o m p a r t i l h a d a ", ~}$ deverão constituir "uma rede de instituições de preservação audiovisual em todo o Brasil" (ABPA, 2016, p. 1-2).

A ideia da articulação em rede aparece também na Declaración de Salvador, escrita por profissionais da Argentina, Brasil e Uruguai reunidos no Seminário Internacional de Preservação Audiovisual, que inicia recomendando a necessidade de "Afirmar uma identidade regional das entidades de preservação audiovisual do Mercosul, através da constituição de uma Rede Regional de Arquivos e Preservadores Audiovisuais". ${ }^{19}$

\footnotetext{
${ }^{18}$ Regional refere-se, aqui, às diferentes regiões do Brasil.

19 O Seminário Internacional de Preservação Audiovisual no Mercosul, realizado na cidade brasileira de Salvador-BA, de 9 a 11 de novembro de 2016, como ação do projeto de pesquisa "Preservação audiovisual entre o global e o local (I): Políticas de preservação audiovisual em países latino-americanos (Argentina, Brasil, Paraguai e Uruguai) e a influência de instâncias transnacionais"
} 


\title{
3. À guisa de conclusão: diversidade como luta
}

\begin{abstract}
$\mathrm{O}$ acesso eqüitativo a uma rica e diversificada gama de expressões culturais provenientes de todo o mundo e o acesso das culturas aos meios de expressão e de difusão constituem importantes elementos para a valorização da diversidade cultural e o incentivo ao entendimento mútuo. (UNESCO, 2005, p. 4).
\end{abstract}

Nesse artigo tecemos algumas reflexões sobre as políticas de preservação audiovisual em países do Mercosul, indagando quais as consequências de sua ausência para a diversidade cultural da região.

Em relação ao Plano Estratégico Patrimonial do Programa Mercosul Audiovisual fomos buscar seus efeitos nas instituições de preservação audiovisual da região em tela, bem como na "ponta", em uma esfera de produção local (no caso, um exercício feito no Estado da Bahia). Nesse sentido, questionamos, em primeiro lugar, de que forma o Plano concorreu para a "conservação do patrimônio audiovisual regional", para "a valorização da memória e das imagens próprias dos países do Mercosul”, para "articular as políticas de integração regional”; ou, pelo menos, em que medida ele operou no sentido de "potencializar as políticas nacionais de preservação" (RECAM, 2013, p. 8 e 10). Se o nexo entre formulações e ações nos parece demasiado tênue, as investigações, contudo, apontam para a pertinência e mesmo a urgência de uma articulação regional.

Para Canclini (1994, p. 99), audiovisual é um dos "novos referentes de identificação coletiva", entretanto, por sua conexão com a produção industrial e com o entretenimento, ele costuma ser excluído dos debates sobre patrimônio, pautados por uma compreensão estreita da palavra. Se, entretanto, considerarmos a produção cinematográfica como parte das expressões artísticas e socioculturais de um povo, a salvaguarda do acervo audiovisual de um país impõe-se por diferentes motivos. Em primeiro lugar, como dito anteriomente, por sua importância para a constituição das cinematografias nacionais diversas. Em segundo, porque a preservação de diferentes modos de expressão audiovisual é essencial para o compartilhamento de uma usina de símbolos, que forma a base para a construção/desconstrução/reconstrução de redes de significados, especialmente no contexto da dominação dos produtos de Hollywood. Importante a possibilidade de experimentação e 
criação de formatos estéticos e narrativos, para além dos modelos hegemônicos e dos produtos comerciais na esfera do Mercosul, composto por países à margem do eixo central da economia e política mundiais, com populaçoes de bases étnico-raciais e culturais bastante diversificadas.

No universo das tecnologias digitais, que trouxe o aumento da produção e do consumo audiovisual e o surgimento inúmeras plataformas e janelas de exibição, é urgente refletir sobre o "valor social e estético das imagens em movimento", sobre as formas de produção da memória específicas do audiovisual, assim como sobre o papel dos arquivos de filmes nesse novo "tempo de compartilhamento" (HEFFNER, 2013).

Abrem-se aqui novos campos de disputa. O que será ou não preservado na esfera nacional? Quem decide? A partir de que referenciais? Em que condições? Se nem mesmo a diversidade da produção audiovisual professional fora do eixo hegemônico do Brasil consegue ser adequadamente preservada,

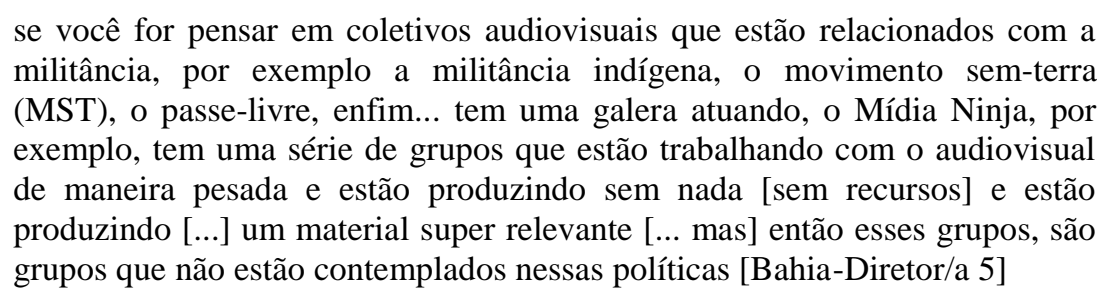

A memória coletiva, lembremos Jacques LeGoff (1996, p. 477), “é um instrumento e um objeto de poder".

Abrem-se, aqui, novos campos de disputa. Em 1989, o diretor estadunidense Martin Scorsese divulgou um manifesto, no qual lamentava que "todo nosso árduo trabalho e nossos esforços criativos de nada valem porque nossos filmes estão desaparecendo". Esse foi o estímulo para a criação de uma fundação, que ajudou a restaurar mais de 800 filmes estadunidenses e 32 filmes de outros 21 países (uma relação de 96\%-4\%). ${ }^{20}$ Em 2005, "Recomendação da União Europeia relativa ao património cinematográfico e à competitividade das actividades industriais conexas", referia-se explicitamente ao "patrimônio cinematográfico" como um "componente importante da indústria cinematográfica e [...sua salvaguarda como uma contribuição] para melhorar a competitividade desta indústria.”

Neste contexto, a preservação dos acervos audiovisuais dos países do Mercosul

\footnotetext{
${ }^{20}$ Cf. <http://www.film-foundation.org>. Acesso em: jul. 2018.
} 
adquire importância estratégica, uma vez que está em jogo definir "quais serão os povos que continuarão a contribuir para [o...] enriquecimento [do patrimônio cultural comum da humanidade] e quais aqueles que serão relegados ao papel de simples consumidores de bens culturais adquiridos no mercado." (FURTADO, 1984, p. 23).

A proteção e a promoção da diversidade cultural precisa deixar de ser um dos "novos lugares comuns das políticas públicas” (ALBORNOZ, 2015, p. 153). É necessário retomar a a ideia de diversidade como "oposto, divergente, contraditório, diferente no sentido ativo" (BERNARD, 2005, 75), se, em um mercado audiovisual dominado por poderosos conglomerados, se intenta minorar a desigualdade entre os diferentes atores. Seja em função de sua dimensão simbólica ou de seu valor econômico, seria estratégico preservar o acervo de imagens em movimento de países do eixo sul. Para isso é imperativo a implementação de políticas culturais efetivas, que produzam resultados concretos e que articulem ações nas esferas transnacionais, nacionais e locais.

\section{Referências}

ASSOCIAÇÃO BRASILEIRA DE PRESERVACAO AUDIOVISUAL. Plano Nacional de Preservação Audiovisual. Disponível em: < http://www.abpreservacaoaudiovisual.org/site /abpa/plano-nacional-de-preservacao.html > . Acesso em: out. 2018.

BAECQUE , Antoine de. Cinefilia - Invenção de um Olhar, História de uma Cultura 19441968. São Paulo: Cosac \& Naify, 2011.

BARROS, J.M.: DUPIN, Giselle; KAUARK, Giuliana. Cultura e Diversidade. Rio de Janeiro: Lumen Juris, 2017.

BERNARD, François de. Por uma redefinição do conceito de diversidade cultural. In: BRANT, Leonardo. Cultura: Globalização e culturas locais. São Paulo: Escrituras Editora/Instituto Pensarte, 2005.

BEZERRA, Laura. O Plano Estratégico Patrimonial do Programa Mercosul Audiovisual e suas influências nas políticas de preservação audiovisual no Brasil. In: III Encontro Brasileiro de Pesquisa em Cultura, 2016, Crato- CE. Anais... . Juazeiro do Norte-CE: Universidade Federal do Cariri, p. 156-166.

Políticas Regionais de Preservação Audiovisual: o Plano Estratégico Patrimonial do Programa Mercosul Audiovisual. In: XI REUNIÓN DE ANTROPOLOGIA DEL MERCOSUR, 2015, Uruguai. Anales... Montevideu: UDELAR, 2015.

Políticas para a preservação audiovisual no Brasil (1995-2010). 2013. Tese (doutorado) - Universidade Federal da Bahia, Instituto de Humanidades, Artes e Ciências Professor Milton Santos, Salvador, 2013. 
BEZERRA, Laura; SANTOS, Tamara Carla. Preservação Audiovisual entre o Regional e o Local. Ou: Para Que Serve Um Plano? In: XII Encontro de Estudos Multisdisciplinares em Cultura, 2016, Salvador-. Anais... .: Salvador-BA. Universidade Federal do Bahia, p. 156-166.

CALABRE. Lia (Org.). Políticas culturais: reflexões e ações. São Paulo: Itaú Cultural; Rio de Janeiro: Fundação Casa de Rui Barbosa, 2009.

CANCLINI, Néstor García. O Patrimônio Cultural e a Construção do Imaginário Nacional. Revista do Patrimônio Histórico e Artístico Nacional, n. 23, p. 95-115, 1994.

EDMONDSON, Ray. Filosofia e princípios da arquivística audiovisual. Rio de Janeiro: ABPA; Cinemateca do MAM-RJ, 2013.

FREY, Klaus. Políticas Públicas: um debate conceitual e reflexões referentes à prática das políticas públicas no Brasil. IPEA. Planejamento e políticas públicas - PPP, n. 21, p. 211-259, 2000. Disponível em:< http://www.ipea.go.br/ppp/index.php/PPP/article/view/89 >. Acesso: mai. 2018

FURTADO, Celso. Cultura e desenvolvimento em época de crise. Rio de Janeiro: Paz e Terra, 1984.

GALVÃO, Maria Rita. La situación del património fílmico em Iberoamerica, Journal of Film Preservation, n. 71, p. 42-61, 2006.

HEFFNER, Hernani; HALLAK, Raquel; HALLAK, Fernanda (Orgs.). Reflexões sobre a preservação audiovisual. Ouro Preto: Universo Produções, 2015.

KAUARK, G.; BARROS, J. M.; MIGUEZ, P. (orgs.) Diversidade Cultural: políticas, visibilidades midiáticas e redes. Salvador: Edufba, 2015.

LE GOFF, Jacques. História e memória. Campinas: Editora da Unicamp, 1996.

MIGUEZ, Paulo. Algumas notas sobre comércio intenacional de bens e serviços culturais. In: BARBALHO, A.; CALABRE, L.; MIGUEZ, P.; ROCHA, R. (Orgs.). Cultura e Desenvolvimento: perspectivas políticas e econômicas. Salvador: Edufba, 2011, p. 57-70.

MOREIRA, F.; BEZERRA, L.; ROCHA, R. A Secretaria do Audiovisual: políticas de cultura, políticas de comunicação. In: RUBIM, Antonio Albino Canelas (Org.). Políticas Culturais no Governo Lula. Salvador: Edufba, 2010, p.133-158.

RECAM. Plan Estratégico Patrimonial do PMA. Buenos Aires, noviembre de 2013. Disponível em: < http://www.recam.org/pma/files/other/164/Plan\%20Estrategico\% 20Patrimonial.pdf>. Acesso em: out. 2014.

ROCHA, Glauber. Revisão Crítica do Cinema Brasileiro. São Paulo: Cosac \& Naify, 2003.

SOUZA, Carlos Roberto de. A Cinemateca Brasileira e a preservação de filmes no Brasil. 2009. Tese (Doutorado em Ciência da Comunicação) - Escola de Comunicação e Artes, Universidade de São Paulo, São Paulo, 2009.

UNESCO. Convenção para a Proteção e a Promoção da Diversidade das Expressões Culturais. Paris, 2005. Disponível em: < http://www.cultura.gov.br/politicas5//asset_publisher/WORBGxCla6bB/content/convencao-sobre-a-protecao-e-promocao-dadiversidade-das-expressoes-culturais/10913>. Acesso em: jul. 2015. 
Recommendation for the Safeguarding and Preservation of Moving Images.

Conferência Geral da UNESCO, Belgrado, 1980. Disponível em: <http://portal.unesco.org/en/ ev.php-URL_ID=13139\&URL_DO=DO_TOPIC\&URL_SECTION=201.html>. Acesso em: jul. 2008.

VIEIRA, Mariella Pitombo. Reinventando sentidos para a cultura: uma leitura do papel normativo da Unesco através da análise da convenção sobre a proteção e promoção da diversidade das expressões culturais. Salvador, 2009. Tese (doutorado) - Universidade Federal da Bahia, Faculdade de Filosofia e Ciências Humanas, 2009.

. Acesso em: 26 julho 2015. (Modelo para Sites). 